\title{
Research on Collective Memory of Chinese Sports Commentary from the Perspective of Social Media-Taking Song Shixiong's Commentary as an Example
}

\author{
Jing li \\ Wuhan Sports University, Wuhan, Hubei, 430079, China
}

Keywords: Social media, Sports commentary, Song Shixiong, Collective memory.

\begin{abstract}
Collective memory is not the "1+1=2" of memory, but the re-emergence and collective cognition of past events or situations of a group in a specific time and space. In big sports events, for those who can't experience the scene in person or get the information directly, the memory of the major sports events that have occurred is mainly from sports commentary or media reports. As a carrier of memory text, the media brings together a group of memories, and today's social media has become a new place of memory. From the perspective of social media, this paper takes the first generation of sports commentator Song Shixiong as a research case, and tries to analyze the text content in social media through the web crawling method to explore the collective memory of the sports commentary in China.
\end{abstract}

\section{About Collective Memory}

\subsection{The proposal of collective memory}

French sociologist Durkheim has put forward the concept of "collective jubilation". He believes that tribal members can show some creativity when they gather together during celebrations, dances and holiday gatherings. Durkheim's student Maurice Halbwachs has put forward the term collective memory in the content of "collective jubilation". Halbwachs believes that the obvious gap between the jubilation period and the daily life period is actually filled and maintained by collective memory. [1] There are two explanations of the word "memory" in the Modern Chinese Dictionary (7th Edition). One is a verb, that is, to remember or recall, the other is a noun, that is, the impression of the past things kept in the mind. What is collective memory? Collective memory is not the sum or synthesis of memory represented by literal meaning. Collective memory is not the " $1+1=2$ " of memory, but the re-emergence and collective cognition of a group of things or scenes in the past in a specific time and space. Although Halbwachs does not clearly define collective memory in his writings, as the founder and pioneer of collective memory research, he believes that collective memory is based on the "now-centered view" and emphasizes its currency.

\subsection{Collective memory is a kind of construction}

For Halbwachs, the past is a social construction, which is, if not all, shaped mainly by current concerns. [2] He says: "We preserve memories of the various periods of our lives. These memories are constantly reproduced; through them, just like through a continuous relationship, our sense of identity stays for a lifetime. But because these memories are a kind of repetition, and because there are different periods in our lives, memories have lost the form and appearance they once possessed." [3] After the German psychologist Ebbinghaus published his experiment report in 1885 by, memory has become one of psychological areas with the most experiments and researches. Some impressions of the past will change over time, and groups will recombine and create it according to different time and space. 


\subsection{Collective memory and its media}

When analyzing the field of collective memory, Li Hongtao (2013) believes that Misztal emphasizes that human memory can only operate in a collective context, and any collective memory needs the support of groups in a certain time and space. [4] This is the focus of collective memory research in a period of time, through daily life, special events, important ceremonies and anniversaries, etc. as a carrier for physical commemoration. Subsequently, through oral communication and literary, photography, books, radio, television, the Internet and the mass media, memory and media have got closer relations. According to Wulf Kanstiner, the history of collective memory will be reshaped into a complex process of cultural production and consumption. Communication and media research methods should be used in the collective memory research, especially in terms of media reception. [5] Who produces the memory, how to produce it and what to produce, etc., should be systematically analyzed through the memory text in the media.

\section{Collective Memory Characteristics of Sports Commentary under Social Media}

Sports commentary is about the interpretation and explanation of sports, describing and commenting on sports events and sports events through language. The sports commentary is spread through the media, and the commentary is closely linked to the media. "Sports commentary is a kind of broadcast media as the main media platform, with sports audience as the target, and oral description, interpretation and evaluation of sports events, so that the audience can better watch the news communication activities of sports events." It is the definition of the sports commentary in the Sports Commentary Review. [6] From broadcast to television and to new media, the media has undergone tremendous changes. The way of explanation has also changed with the habit of the audience receiving information.

\subsection{In the era of broadcasting, listeners remembered by receiving one-way picture memory of sound symbols}

On January 8, 1951, the Soviet national men's basketball team visited Shanghai for three games. The three games were jointly presented by Zhang Zhi of Shanghai People's Broadcasting Station and a film crew of Shanghai Film Studio, which is identified as the beginning of the broadcast stage of the new China sports event.

"His voice is high, sharp, fast and full of passion, which attracts the audience. The situation on the field can be introduced in time. For instance, Number xxx is taking the ball and passing it to Number xxx. He is tireless, making the audience feel like being served. Serving the people is an excellent quality that came from the people in the Mao era." __Advancing Bravely 1977, Tianya Community Client, June 27, 2015

In the era of broadcast broadcasting, the only way for the audience to know the game information was through the voice of the commentator, who often recorded all the statistics about the game in a notebook and reported it to the audience. The things he saw and heard were broadcast quickly and without error.

Table1. Social Platform Text Keyword Frequency Statistics

\begin{tabular}{|c|c|c|c|c|c|}
\hline \multicolumn{2}{|c|}{ Noun } & \multicolumn{2}{c|}{ Verb } & \multicolumn{2}{c|}{ Adjective } \\
\hline $\begin{array}{c}\text { Women's } \\
\text { volleyball }\end{array}$ & 122 & Comment & 214 & Famous & 20 \\
\hline Teacher & 91 & Announce & 28 & Continuous & 14 \\
\hline Lang Ping & 84 & Host & 22 & Happy & 13 \\
\hline China & 71 & Read & 14 & Many & 11 \\
\hline Sports & 49 & Broadcast & 14 & Complete & 9 \\
\hline
\end{tabular}

For the keyword "Song Shixiong", around 25,000 words of relevant information on social networking platforms such as Weibo, WeChat and Post Bar were collected through the web crawler 
tool in 2017. Through text analysis, the most mentioned nouns by netizens are "women's volleyball", "teacher", "Lang Ping", "China" and "sports", which prove that "women's volleyball" and "Lang Ping" were most impressive to the audience in the era of Song Shixiong's commentary. And Song Shixiong's personality is respected by his peers and audience.

\subsection{In the TV era, viewers relied on emotional memory of non-verbal symbols}

June 19, 1958 saw a live broadcast of the Bayi Men and Women's Basketball Team and the Beijing Basketball Team's exhibition match on Beijing TV, which was explained by the sports commentator Zhang Zhi. This is where the TV broadcast of the Chinese sports competition was born. In the women's volleyball final of the Los Angeles Olympics in 1984, the Chinese Women's Volleyball Team defeated the US Team 3-0 and won the Olympic champion for the first time. The classic commentary of this competition is also one of the collective memories of sports audiences. The average speed of 6 and a half words per second by Song Shixiong is known as the fastest speech commentary.

The media of sports commentary has changed from broadcasting to television, so that the identity of the commentator has also changed. In the era of radio broadcasting, the audience listened to and could only know what the narrator said. The main content and detailed information of the arena are delivered by the commentator. The advent of the era of television broadcasting has given audiences a chance to get close to the game, and audiences can intuitively receive various information of a game through non-verbal symbols.

The commentator's own language and emotions is the key to the service. "Short, straight and fast", "Iron Hammer", "Setter", "Backward flight" and "Chinese Team Score" are the collective memory of sports audiences for Song Shixiong in the TV era. Song Shixiong's high-pitched male voice and extremely fast and clear language, combined with the auxiliary broadcast of the picture, make the commentary effect better and the audiences more impressed.

The appearance of television pictures has made the live broadcast of sports games more abundant. Visual symbols are a direct reflection of the objective world and more specific than the language, so that audiences can receive information first without hearing. Visual symbols attract audiences in the form of direct impact. The audience directly understands the meaning and viewpoint of the picture, and the receiving psychology of audiences is also changing. The athlete's physique, fierce confrontation and touching pictures can directly attract the attention of the audience, as well as trigger emotions. In the age of sound, the narrator made audiences immerse with voice, and in the TV era, audiences directly immerse themselves in the arena with visual symbols. Audiences repeatedly present pictures and videos as a new form of memory.

\section{In the new media era, the audience and the media interact with each other}

The emergence of new media such as the Internet, the client, and the live broadcast platform has brought more opportunities to the commentator and more expressing space. In the era of "all-all communication", audiences' requirements for commentary have reached an unprecedented height. The audience hopes the commentary to be more grounded in more diverse ways. Fans can speak for the first time, so the commentator's job has changed from a commentary voice into a voice for the fans. In the Internet age, the audience's thinking needs to be translated into user thinking, to serve the user on the one hand and interact with the user on the other hand. Through two-way communication, user information and user feedback are obtained to serve the user better. In the new media era, the audience is both a recipient and a communicator, and the user has a dual role identity.

Through the semantic network diagram, the collective memory of the audience for Song Shixiong's commentary is not limited to one aspect. In the blank period of daily life and specific dates, relevant memories are triggered by important events or related programs. For example, the collective memory from "sports" to "Zhu Ting", "interpretation" and "eloquence" is not independent, but closely related to the events. The theoretical focus of collective memory suggests that the generation is the framework of collective memory. Those who have profound memories of the radio 
broadcasting era believe that full enthusiasm and clear expression are the key to good commentary, and collective memory affects the judgment of audiences. "I can't hear what the commentator is saying and I want to turn off the TV. " (Weibo content)

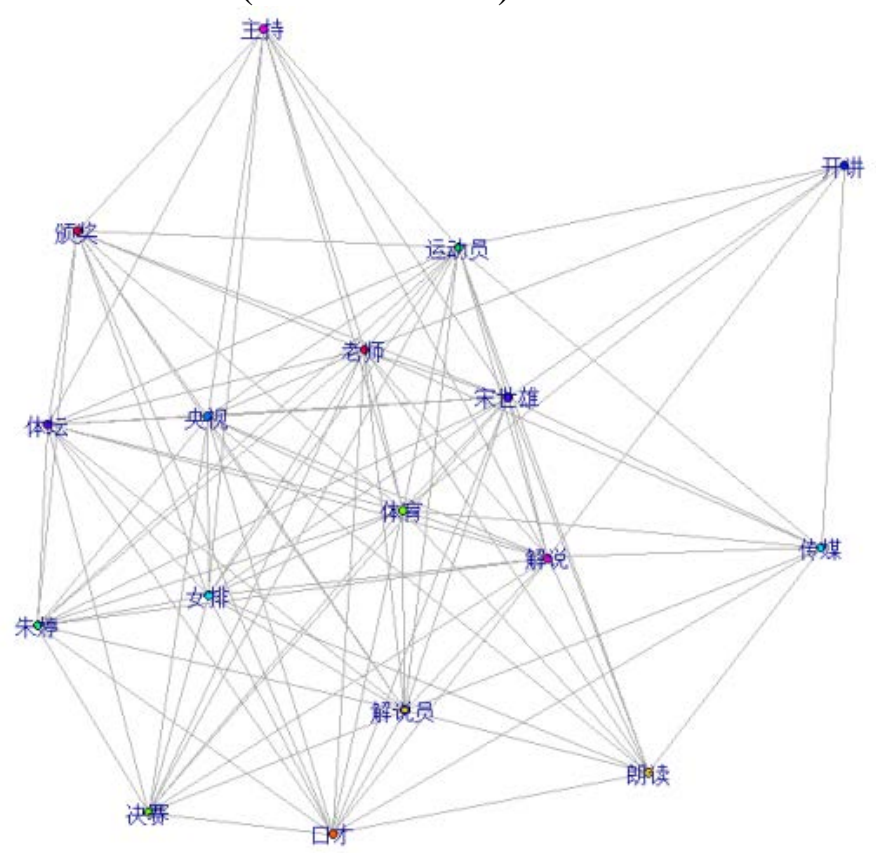

Figure 1. Semantic Network Diagram

In the era of radio and television, the feedback from audiences was mainly presented in the form of letters, telephone calls and text messages. Audiences could only wait to see whether the feedback could be received by the media and the opinions were adopted. Whether the commentator's commentary was accepted and approved by audiences and how it should be improved were also needs to be obtained from the waiting letters. The media was often troubled by the "invisibility" of audiences. (10) Belgian researcher Roger Krauss (1968) divides the messages received by the audience into five levels, the provided message, acceptable message, received message, noticed message and internalized message. The provided message refers to almost all potential audiences who may receive the message. The acceptable message is the maximum range that is actually received, and audiences receiving range is narrowed successively. In the new media era, the media has solved the continuity of the five levels, and adopted interactive forms such as messages, comments, and instant messages to allow each level of messages to arrive at any time.

A considerable part of audiences' grasp of the world comes from visual viewing, and viewing is not a passive process, but a process of active discovery. (11) In the new media era, audience perceptions have a strong initiative in media use, selection and commentary. At the same time, the content and methods of media communication are influenced by the attitude of the audience. Audiences communicate with the communicator in an equal identity. The sense of interaction and participation is enhanced through an open online platform to gain awareness of the event. In the new media era, through the two-way communication of the media and users, and the direct communication between users, collective memory has generated more diverse memory elements.

\section{Changes in Collective Memory from the Perspective of Audiences}

With the commentator as the narrator and the media as the narrative angle, the narrative framework is also changing in the new media era. Sociologist Goffman points out in Framework Analysis Art, "The framework is the psychological model that people use to explain the external objective world; all of our induction, structure and interpretation of real life experience depend on a certain framework; framework enables us to identify, understand, summarize, and support time and information." Collective memory changes in the process of construction as the narrative framework 
changes. The main body and content constructed by collective memory will be tilted to the perspective of the audience, the collective memory of which has more symbols and more fragmented forms.

In the era of Internet + , the threshold of self-media is low. In this era when "everyone has a microphone", collective memory will be constructed and repeatedly constructed in the active participation and instant expression of the public.

It should be noted that in the media age of information-telling-broadcasting, there are more and more elements to obtain memory, but the elements that make groups remember will change as events change. Meanwhile, elite memory and Internet celebrity memory affect collective memory easily. Physical practice is the key to transmitting social memory. In the new media era, memory is dynamically constructed in interaction, so the stability of the preservation and transmission of collective memory deserves further study.

\section{Conclusion}

Through the text analysis of the social platform, combined with the theory of collective memory, the author has found that audiences have relatively clear collective memory for the voice of the sports commentators in the 1980s. The text content retrieved by the keyword "Song Shixiong" is closely related to the sports events he have explained, and has formed a certain memory field. Due to the emergence of Internet+, the specific title of "teacher" is the collective memory that Song Shixiong's personal quality brings to the audience. (Figure 2) When Song Shixiong participated in the program "Reader" or related evening parties, people will participate in related events and project memory through discussion. This is a method of constructing the collective memory of Song Shixiong.

Due to the limited research methods used by the author, the relevant texts collected should have been more abundant. In the follow-up study, the construction of sports commentary in social media will be further studied.

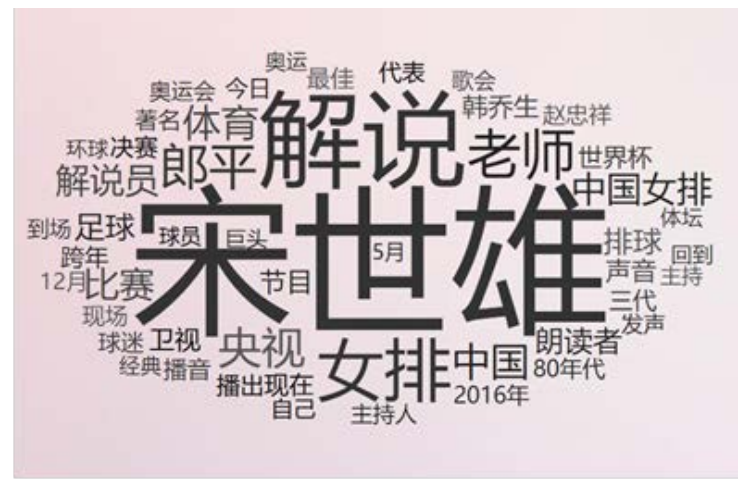

Figure 2. Word Cloud Illustration

\section{References}

[1] Morris Halvah, Harvard, Bi Ran, et al.: On Collective Memory, Shanghai People's Publishing House, 2002

[2] Li Hongtao. History of yesterday Today's News-Media Memory, Collective Identity and Cultural Authority, Contemporary Communication (Chinese Version), 2013(5): 18-21.

[3] Kansteiner W. Finding Meaning in Memory: A Methodological Critique of Collective Memory Studies, History \& Theory, 2010, 41(2): 179-197.

[4] Zhang Desheng: Sports Commentary, Huazhong University of Science and Technology Press, 2016 edition.

[5] Vadim: On the Change of the Role of Sports News Interpreters in China and Russia--Centered on the Chinese and Russian Football Interpretations, Shanghai Normal University, 2016. 
[6] Wei Wei: Discursive Turn, Personality Appeal and Fair Position - Research on TV Sports Interpretation, Sichuan University, 2009.

[7] Song Shixiong: Wuhan Sports Institute "Internet + Times Sports and Media Summit Forum" Lecture December 2015.

[8] Dennis McGuire: Audience Analysis, Renmin University of China Press, 2011 Edition.

[9] Jin Xia: The Visual Cultural Turn in the Age of Reading Pictures, Journal of Hubei University for Nationalities(Philosophy and Social Sciences Edition), 2009, 27(3): 91-96. 